\title{
Research on Extrusion of Rubber Composites Reinforced by Short Fibers Orientation Based on FEA
}

\author{
Dewei Zhang ${ }^{1,2}$, Chuansheng Wang ${ }^{1,2 *}$, Bo Shen ${ }^{1,2}$, Shaoming $\mathrm{Li}^{1,2}$ and Huiguang Bian ${ }^{1,2}$ \\ ${ }^{1}$ Shandong Provincial Key Laboratory of Polymer Material Advanced Manufacturing Technology Qingdao University of Science \& \\ Technology, 266061, Qingdao, China \\ ${ }^{2}$ College of Electromechanical Engineering, Qingdao University of Science \& Technology, 266061, Qingdao, China
}

\begin{abstract}
In recent years, rubber composites reinforced by short fibers has been researched deeply, because of its good performances such as higher wear resistance, higher cut resistance and so on. Some research results indicated that if short fibers get orientation in rubber composites, the performances of rubber products could be promoted greatly. But how to make short fibers get orientation in rubber matrix during extrusion is still a real problem. And there are many parameters affect the short fibers orientation. So, in this paper, the effects of die structure including expansion-die and dam-expansion-die on extrusion flow field of short fiber and rubber composite material during extrusion process has been researched by Polyflow. And the FEA results about the pressure field, velocity field and the velocity vector of the rubber composites flow field indicate that, comparing with expansion-die and the dam-expansion-die, the latter one is better for the extrusion process of rubber composites and making short fibers get radial orientation in rubber matrix.
\end{abstract}

\section{Introduction}

Rubber composites which could be reinforced by short fibers has been started to be researched from 1970's. Because it combines the rigidity of short fiber and elasticity of rubber together, the rubber composites reinforces by short fibers have became a new kind of high polymer composite material[1-4]. As a result, the rubber composites has been researched deeply and used widely in recent years[5-12]. Moreover, some research results showed that if short fibers get orientation in the rubber composites material, the rubber products using properties could be promoted. For example, if short fibers get radial orientation tire tread products which means the orientation direction of short fibers is at the radial direction of tiers, or at the thickness direction of tire tread, the wear resistance ability, rolling resistance ability, tearing resistance ability, etc of tire tread could be promoted greatly. During the manufacturing process of rubber composites, the die structure is one of the most important factors that impacts short fibers radial orientation during extrusion process. Therefore, in this paper, the effects of two kinds of different die structure which is dam-die, expansion-die on extrusion flow field of rubber composites have been researched by FEA method using Polyflow. And the analyzed flow fields were pressure field, velocity field and velocity vector.

\subsection{Physical model and FEM model}

The physical model and FEM model must to be established before FEA. The physical model is the material that fulls of the die channel, which have been shown in the Fig.1. And the FEM model is the results of net dividing, which have been shown in the Fig.2.

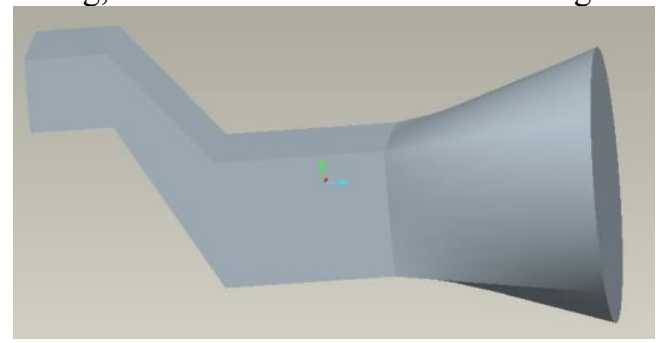

(a)Expansion-die

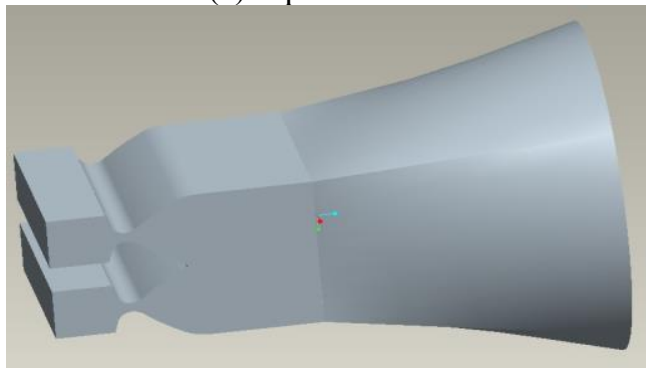

(b)Dam-expansion-die

Fig. 1. Physical model of FEA

\section{FEA models}

\footnotetext{
"Corresponding author: zhangdewei1421@163.com,wcsmta@qust.edu.cn
} 


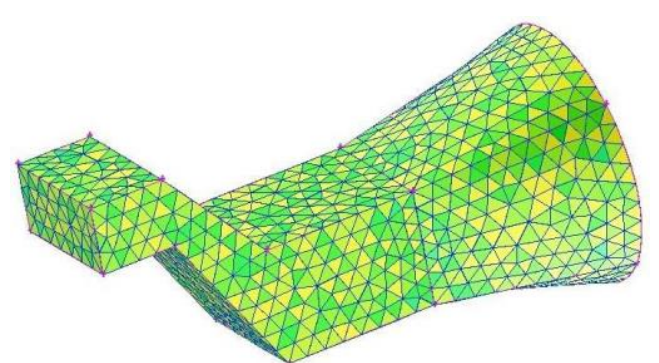

(a)Expansion-die

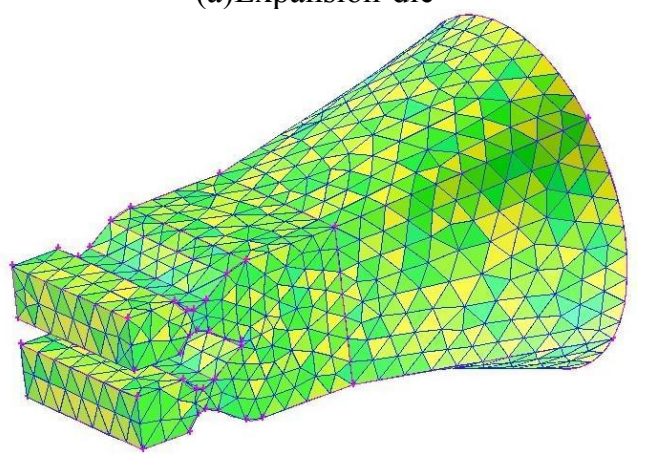

(b)Dam-expansion-die

Fig. 2. FEM model of FEA

\subsection{Boundary conditions and physical parameters}

The boundary conditions and physical parameters that have been set for the FEA process have been shown in the Table 1 and Table 2.

Table 1 Dies boundary conditions

\begin{tabular}{cc}
\hline $\begin{array}{c}\text { Die flow amount } \\
\left(\mathrm{mm}^{3} / s\right)\end{array}$ & $\begin{array}{c}\text { Velocity in the } \\
\text { channel } \\
\text { face }(m / s)\end{array}$ \\
\hline 40 & 0 \\
\hline
\end{tabular}

Table 2 Physical parameters for FEA

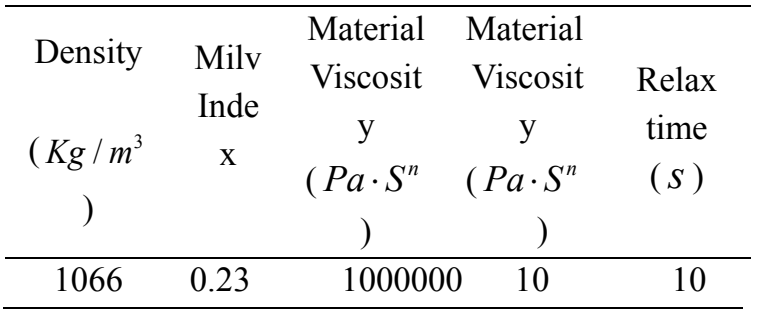

\section{Analysis results and discussion}

\subsection{Pressure field}

The effects of the two kinds of structure which were expansion-die and dam-expansion-die on extrusion process pressure field of rubber composites have been shown in the Fig. 3.
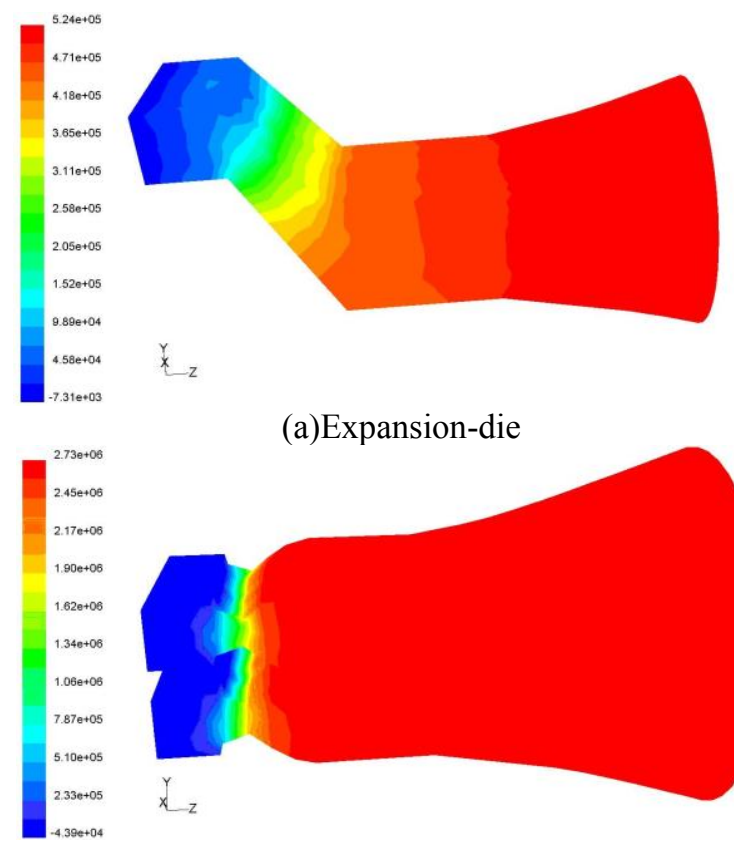
$x_{z}$

(a)Expansion-die

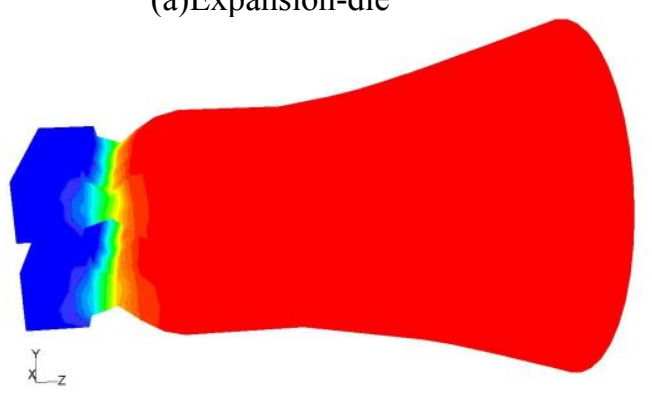

(b)Dam-expansion-die

Fig. 3. FEA Results of Pressure Field

As vividly shown in the Figure 3, at the same extrusion conditions, it is obviously that the pressure field of dam-expansion-die is changing more intensely than that of expansion-die. And the maximum pressure value of dam-expansion-die is about $2.73 \mathrm{MPa}$, while the maximum pressure of expansion-die is $0.52 \mathrm{Mpa}$.

As a result, at the same extrusion conditions, on one hand, the dam-expansion-die could establish a higher die pressure for extrusion of rubber composites. Due to it is necessary to make rubber material with short fibers get compressed for short fibers get radial orientation in rubber matrix, so a higher die pressure is also needed. On the other hand, the dam-expansion-die pressure change is intense, which indicate that the rubber material could expand as fast as possible after passing the dam structure, as a result, short fibers would turn to a bigger angle with the expanding of rubber material than the situation of rubber material expanding slowly. Therefore, the dam-expansion-die is could establish a better pressure field for radial orientation of short fiber than expansion-die.

\subsection{Velocity field}

The effects of the two kinds of structure which were expansion-die and dam-expansion-die on extrusion process velocity field of rubber composites have been shown in the Fig. 4.

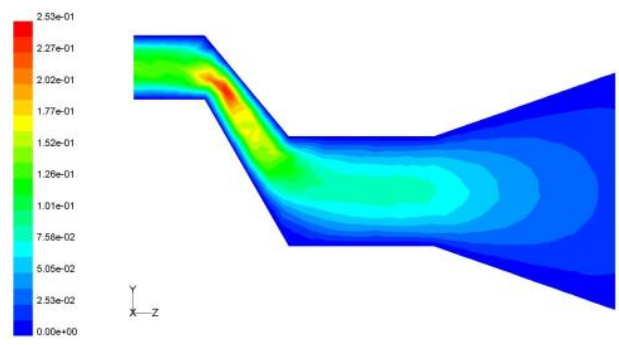




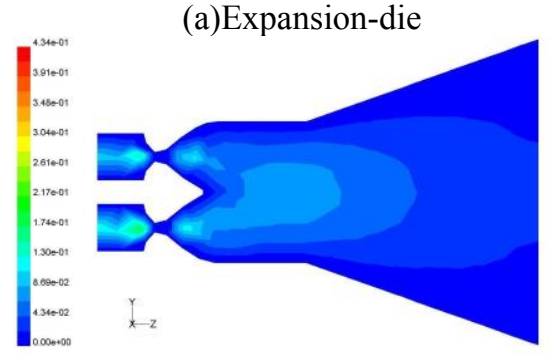

(b)Dam-expansion-die

Fig. 4. FEA Results of Velocity Field

As what have been shown in the Figure 4, at the same extrusion conditions, the velocity field of dam-expansion-die is steadier than that of expansion-die, which means the change of velocity value is not intensely. And the maximum velocity value of dam-expansion-die is about $43.4 \mathrm{~mm} / \mathrm{s}$, while the maximum velocity value of expansion-die is $25.3 \mathrm{~mm} / \mathrm{s}$.

As a result, at the same extrusion conditions, not only could the dam-expansion-die have a bigger extrusion speed, which does not cut down the production ability of extruder, but also the velocity field of the dam-expansion-die is steadier than that of expansion-die. If the changing of velocity value is intense, such as the velocity field of expansion-die which has been shown in the Figure 4, the flow of rubber material with short fibers would generate turbulence, this would impact radial orientation of short fibers in the rubber composites during the extrusion process. So, the dam-expansion-die has a bigger velocity value and a steadier velocity field than those of the expansion-die. Therefore, the dam-expansion-die is better for the extrusion of rubber composites to make short fibers get radial orientation.

\subsection{Velocity vector}

Considering velocity is a vector, and the Figure 4 just only showed the velocity value of the velocity field which generated during extrusion process of rubber composite. And there was no velocity direction. So the velocity direction of the two kinds of structure which were expansion-die and dam-expansion-die has also been analyzed based on FEA, and the results have been shown in the Fig. 5.

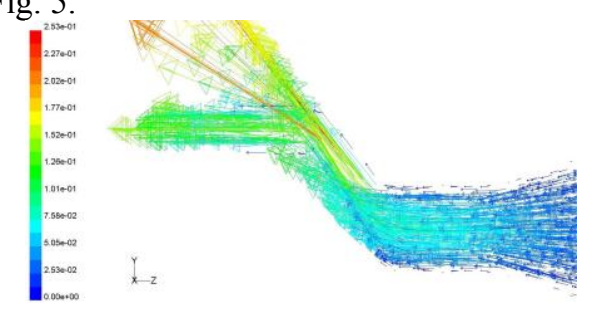

(a)Expansion-die
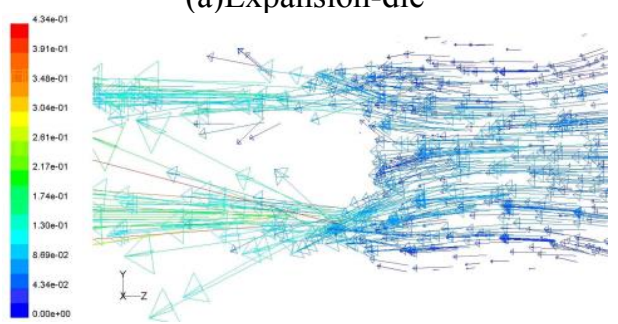

(b)Dam-expansion-die

Fig. 5. FEA Results of Velocity Vector

As what have been vividly shown in the Figure 5, the velocity direction could be seen directly together with the velocity value. Only considering the velocity direction, at the same extrusion conditions, the direction angle of dam-expansion-die is bigger than that of expansion-die, which means the short fibers turn direction of dam-expansion-die or dam-die is better than that of expansion-die, this also means the dam-expansion-die could make short fibers get better radial orientation during the extrusion process of rubber composites.

\section{Conclusions}

The conclusions about effects of the two kind of different structure which were dam-expansion-die and expansion-die on extrusion flow fields of rubber composites during extrusion process could be drawn as following,

1) At the same extrusion conditions, the dam-expansion-die could establish a bigger pressure field that changes intensely and a steadier velocity field that has a bigger velocity value than the expansion-die. Moreover, the velocity direction angle of dam-expansion-die is bigger than that of expansion-die.

2) The effects of die structure on extrusion field of rubber composites could be researched easily and directly and vividly without experiments, avoiding the bad effects of some experimental factors. Also, the design of die structure can be changed according to the FEA results. As a result, the design efficiency and quality can be promoted.

\section{Acknowledgements}

The authors would like to thank the National Natural Science Foundation of China (NO. 50775116), Project of Shandong Province Science and Technology Development Program (NO. 2013TD16006), Project of Shandong Province Higher Educational Science and Technology Program (J15LB73) for finance support.

\section{References}

1. Li H T. Development of Short Fiber-rubber Composite Material[J]. Modern Rubber Technology, 2006, 32(4):5-12

2. Wang C S, Liu C J, Bian H G. Radial Orientation Mechanism and Experimental Research of Short Fiber in Tread Compound[J]. Journal of Donghua University, 2009, 26(6):666-672.

3. Wang C S, Zhang D W, Bian H G. Effects of Mixing Parameters on Properties of Short Fiber and Rubber Composite Material[J]. Journal of Functional Materials, 2011, 42(8): 1448-1452. 
4. Nuttapong $H$, Sombat $T$ and Taweechai A. Improving the mechanical properties of short pineapple leaf fiber reinforced natural rubber by blending with acrylonitrile butadiene rubber[J]. Polymer Testing, 2017, 57:94-100

5. Pitchapa $P$, Sombat $T$ and Taweechai A Comparative study of natural rubber and acrylonitrile rubber reinforced with aligned short aramid fiber[J]. Polymer Testing, 2017, 64:109-116

6. Zhang D W, Wang C S, Lin G Y. Effects of Rotor Speed on Manufacturing Process of Short Fiber-rubber Composite Material[J]. Advanced Materials Research, 2011, 211(1): 350-355.

7. Zhang D W, Wang C S, Lin G Y, etc. Effect of Die Structure on Radial Orientation of Short Fiber in Tire Tread and its Performance[J]. Key Engineering Materials, 2012, 501(1): 247-252.

8. Li Li, Wang Chuansheng, Zhang Dewei, Effects of Radial-Orientation-Die Structure Parameters on Properties of Short Fiber and Rubber Composite Material, Journal of Donghua University (Eng. Ed), 2014, 31(3): 249-255

9. L. Liu, L.Q. Zhang, Z.X. Feng, Development of Green Tires, J. China Rubber Industry. 46(1999)245-248.

10. C.S. Wang, C.J. Liu, H.G. Bian, Radial Orientation Mechanism and Experimental Research of Short Fiber in Tread Compound, J. Journal of Donghua University. 6(2009)666-672.

11. Rijpkema B. The use of short fiber to reduce the rolling resistance of tires $[\mathrm{J}]$, Plastomere Elastomere Duromere, 1994, 47(10): 748 752

12. Walker L A, Pans W, Harber John B et al.. Santoweb fiber reinforcement of ruber compounds[J] , Kautachuk Gummi Kunststoffe, 1985, 38(6): 494 612

13. Datta R N, Peters M. Approaches to Improve Cut/Chip/Chunk Resistance in Truck and Off-the-road Tread Compounds [C]. Symposiums of International Rubber Conference, 2004, 158-165.

14. Li G F, Yang P. Application of Short Fiber-rubber Composites in Rubber Pipes[J]. Ningxia Chemicals, 1994, 1: 1-4.

15. Liu Z J. Application of Nylon Fiber/CR/EPDM Composite Material in Rubber Dam[J]. China Synthetic Rubber Industry, 1997, 20(5): 311-312.

16. Liu J W. Application of Polyester Fiber in Rubber Belts[J]. Special Purpose Rubber Products, 2003, 24(1): 25-40 